\title{
O paradigma social e o tempo do conhecimento interativo: perspectivas e desafios para a arquitetura da informação pervasiva
}

Angela Halen Claro Bembem

Bacharel em Biblioteconomia pela UNESP.Mestre em Ciência da Informação pela UNESP Doutoranda em Ciência da Informação pela UNESPBibliotecária na Reitoria do Instituto Federal de Educação, Ciência e Tecnologia de São Paulo (IFSP)

Henry Poncio Cruz de Oliveira

Graduado em Física pela Universidade Federal da Paraíba . Mestre em Ciência da Informação pelo Programa de Pós-Graduação em Ciência da Informação da UFPB.Doutor em Ciência da Informação pelo Programa de Pós-Graduação em Ciência da Informação da UNESP.Professor Adjunto no Departamento de Ciência da Informação (DCI) da Universidade Federal da Paraíba (UFPB)

Plácida Leopoldina Ventura Amorim da Costa Santos

Bacharel em Biblioteconomia pela UNESP. Mestre em Ciência da Informação pela PUC de Campinas, e doutora em Semiótica e Lingüística Geral pela FFLCH/USP e livre-docente em Catalogação pela UNESP.. Docente permanente do Programa de Pós-Graduação em Ciência da Informação da FFC/UNESP. Vice-Lider do Grupo de Pesquisa Novas Tecnologias em Informação (GP-NTI).

http://dx.doi.org/10.1590/1981-5344/2520

A possibilidade de disponibilização de informações em ambientes informacionais acessados pela diversidade de suportes e tecnologias requer um repensar da Ciência da Informação quanto à chamada Arquitetura da Informação clássica. O surgimento de uma Arquitetura da Informação Pervasiva, que vai além dos limites da Web, apresenta desafios à pesquisa e ação na Ciência da Informação. Para o entendimento dessa recente disciplina no escopo da Ciência da Informação é necessário regatar a compreensão dos tempos e paradigmas que estruturam essa ciência, a fim de que se esclareça o contexto dessa 
disciplina, bem como suas possibilidades de atuação no escopo da Arquitetura da Informação Pervasiva.

Palavras-chave: Arquitetura da informação. Arquitetura da informação pervasiva. Tempos da ciência da informação. Paradigmas da ciência da informação.

\title{
The social paradigm and the time of interactive knowledge: prospects and challenges for pervasive information architecture
}

\begin{abstract}
The possibility of providing information in information environments accessed by diversity of media and technologies requires a rethinking of Information Science as the called classical Information Architecture. The emergence of a Pervasive Information Architecture, which goes beyond the limits of the Web, presents challenges to research and action in Information Science. To understand this recent discipline in the Information Science scope is necessary to rescue the understanding of the times and paradigms that shape this science in order to clarify the context of this discipline, as well as their possibilities of action within the scope of the architecture of Pervasive Information Architecture
\end{abstract}

Keywords: Information architecture. Pervasive information architecture. Times of information science. Paradigms of information science.

Recebido em 24.08.2015Aceito em 17.112015

\section{Introdução}

A Ciência da Informação, como ciência social aplicada, visa à compreensão dos aspectos sociais do mundo humano, direciona-se a entender a problemática social da informação, e é voltada para o sujeito social que procura e necessita dessa informação (LE COADIC, 2004).

A existência e evolução da área estão baseadas, segundo Saracevic (1996), em três características. A primeira delas é o fato de a Ciência da Informação ser interdisciplinar por natureza. É uma área que está inexoravelmente relacionada às tecnologias da informação, de forma que é possível afirmar que o imperativo tecnológico determina essa ciência, atribuindo mudanças da chamada sociedade moderna para uma sociedade 
da informação ou sociedade pós-industrial. Além disso, essa ciência é componente ativo e determinador na evolução da sociedade da informação, também denominada sociedade do conhecimento, sociedade pós-industrial ou ainda sociedade pós-moderna.

A sociedade pós-industrial apresenta um desdobramento sóciocultural que pode ser denominado como pós-modernidade. Para Oliveira (2014, p. 43), a pós-modernidade é:

[...] um estado de contínua e complexa tentativa de ruptura com as visões iluministas e da revolução industrial, que estruturaram o modelo moderno de pensar, de fazer ciência, de racionalizar educação, de organizar a sociedade, de disseminar informação e de produzir tecnologia.

Especificamente os dois últimos aspectos produzem uma aproximação entre a Ciência da Informação e a Pós-modernidade, uma vez que a área atua explicitamente com o estudo e aplicação da disseminação da informação, valendo-se para tanto, no contexto atual, de tecnologias da informação e comunicação para a viabilização de tal processo.

Nesse contexto de pós-modernidade repensar as noções de tempo e espaço se torna fundamental. Isso porque, no que diz respeito à disseminação da informação, a predominância tecnológica permite que, nos ambientes informacionais estruturados digitalmente, a informação seja acessada quase que no mesmo tempo em que é requerida, fato que faz com que o tempo de resposta da informação tenda à zero. Já a desterritorialização dos estoques de informação permite que a informação digital esteja em muitos lugares ao mesmo tempo. Os fluxos de informação encaminhados por redes digitais, e que estão presentes no processo de desterritorialização, fazem com que não se tenha mais um ponto de referência exato de onde os conteúdos informacionais estejam.

Essa informação presente em todo o espaço, e com tempo de resposta antes não visto, deve ser acessada de forma adequada por parte daqueles que dela necessitam. Tal acesso pode ser permitido por dois principais fatores, sendo eles a forma como essas informações são representadas e a forma como são apresentadas.

No que se refere à apresentação da informação, entende-se que no campo da Ciência da Informação, a Arquitetura da Informação é uma das principais disciplinas, sendo ela responsável pelo estudo e implementação de recomendações que permitam que os conteúdos sejam disponibilizados, encontrados e acessados de maneira satisfatória pelos usuários.

A partir da perspectiva de Morville e Rosenfeld (2006, p.4, tradução nossa), a Arquitetura da Informação pode ser definida a partir de quatro aspectos: 
1. O desenho estrutural de ambientes informacionais compartilhados;

2. A combinação de sistemas de organização, rotulagem, busca e navegação em web sites e intranets;

3. A arte e ciência de estruturar produtos de informação e experiências que permitam usabilidade e encontrabilidade;

4. Uma disciplina emergente e comunidade de prática focada em trazer princípios de desenho e arquitetura para o ambiente digital.

Considerando a formação em Biblioteconomia dos autores citados, pode-se retomar o pontuado por Camargo e Vidotti (2006) que a Arquitetura da Informação está relaciona a duas áreas: à Biblioteconomia, por meio dos métodos de organização, classificação e recuperação da informação; e à Arquitetura, valendo-se da exibição de espacialidade. A unificação dessas duas abordagens utiliza as tecnologias da informação e comunicação, sendo a Internet a tecnologia predominante.

A análise do exposto por Morville e Rosenfeld (2006) mostra que a Arquitetura da Informação é apresentada exclusivamente como uma proposta para os ambientes digitais. Todavia, como descreve Oliveira (2014, p.19) "a Arquitetura da Informação tem sido usada como um vetor para o melhoramento do acesso e do uso da informação em ambientes analógicos ou digitais desde a década de 1980". Tal fato revela que a disciplina em questão vai além do ambiente digital.

Considerando que no atual momento de novas dimensões de tempo e espaço as informações estão em todos os lugares, tanto em ambientes tradicionais como nos digitais, e também em ambientes híbridos, apenas as recomendações oriundas da Arquitetura da Informação clássica não são suficientes. Faz-se necessário a compreensão de uma Arquitetura da Informação que vá além dos ambientes digitais, que esteja consonante com ele, mas que o ultrapasse. Nesse sentido Oliveira (2014, p. 18, grifo nosso) afirma que "emerge um movimento tecnológico de integração de ambientes físicos com ambientes de informação digital, por meio da criação de camadas informacionais que os interseciona, facilitando a experiência do sujeito ao percorrê-los". Dessa forma, observa-se que a finalidade desse novo movimento tecnológico é justamente a facilitação da experiência do sujeito ao percorrer a integração dos sistemas de informação.

Para Souza e Pádua (2014, p. 69) "o ambiente informacional híbrido é um espaço de ressignificação permanente onde o usuário é o principal agente [...]". Com isso vê-se que esse novo momento tecnológico de espaços híbridos, a facilitação da experiência do sujeito na interação com os ambientes e recursos neles disponíveis é predominante, pois os sujeitos são os principais agentes desse contexto. Ou seja, os sujeitos estão no centro da definição desses ambientes, são eles e suas 
necessidades informacionais que devem ser considerados para existência e manutenção desses ambientes.

A esse novo movimento tecnológico, no contexto da estruturação e organização da informação em ambientes híbridos, dá-se o nome de Arquitetura da Informação Pervasiva. Essa, como mostra Oliveira (2014), é uma abordagem vinculada à Arquitetura da Informação, a qual é considerada como disciplina científica pós-moderna.

No contexto da Arquitetura da Informação Pervasiva, nota-se que a interação do sujeito com os ambientes informacionais híbridos é uma das principais preocupações. Nesse sentido, sua inserção também no campo da Ciência da Informação se faz pertinente. Essa perspectiva remete-nos a considerar que a Arquitetura da Informação Pervasiva pode-se ser compreendida no contexto do Paradigma social da Ciência da Informação apresentado por Capurro (2003), o qual considera o sujeito e seus contextos para o desenvolvimento de estruturas de recuperação da informação; e no tempo do conhecimento interativo definido por Barreto (2002; 2008), uma vez que esse se caracteriza pelas tecnologias da informação e comunicação como modificadoras da condição da informação e da comunicação.

Tendo em vista isso, tem-se como proposta discorrer sobre a Arquitetura da Informação Pervasiva, apresentando-a como abordagem que pode ser compreendida no âmbito do Paradigma Social da Ciência da Informação e no tempo do conhecimento interativo, a fim de compreender como 0 aporte epistemológico dessa ciência pode servir como fundamentação para a consolidação de uma Arquitetura da Informação Pervasiva.

Para traçar tal aproximação, optou-se como procedimento metodológico pela análise exploratória e descritiva, sendo as discussões encaminhadas pelo aspecto bibliográfico documental.

\section{Da arquitetura da informação para uma arquitetura da informação pervasiva}

Para a compreensão dos caminhos da Arquitetura da Informação Pervasiva faz-se necessário resgatar o que se entende por Arquitetura da Informação. O conceito aparece com força nos trabalhos do arquiteto Richard Saul Wurman em 1976', que segundo Albuquerque e LimaMarques (2011), visava abordar a informação numa concepção de ciência e arte. Os autores apontam que Wurman, a partir dessa concepção, conceituou Arquitetura da Informação como sendo a arte e a ciência de se criar orientações para espaços organizados.

Para Albuquerque e Lima-Marques (2011) a visão de Wurmam expande o conceito da arquitetura tradicional, uma vez que se destina aos

\footnotetext{
1 Wurman escreveu juntamente com Joel Katz o artigo intitulado Beyond graphics: the architecture of information. O trabalho foi publicado pelo AIA Journal, a partir de uma conferência ocorrida em 1976, durante o evento do American Institute of Architecture (AIA). Naquele ano o tema do evento era a Arquitetura da Informação.
} 
espaços informacionais. Perceber a Arquitetura da Informação sobre esse prisma traz duas implicações, apontam os autores. A primeira delas é o fato da Arquitetura da Informação se direcionar a resolver questões análogas ou modificadas da Arquitetura tradicional. Além disso, essa disciplina, por ser abrangente, abarcaria todos os espaços e coleções de informação, de forma que nada ficaria de fora do seu escopo.

Conforme aponta Haverty (2002), a Arquitetura da Informação pode ser considerada campo, mas não é ainda disciplina. Isso porque, conforme Haverty (2002), uma disciplina formal requer uma construção teórica profunda, e teoria orientada aos trabalhadores de uma dada comunidade. Já o campo, é uma área de interesse acadêmico que se baseia na teoria, a qual, geralmente, é oriunda de áreas correlatas.

Em contraponto com defendido por Haverty (2002), Oliveira (2014) aponta que a interdisciplinaridade presente na Arquitetura da Informação, característica que denota para Haverty (2002) o status da área não ser uma disciplina, é um dos elementos que justifica para Oliveira (2014) o fato da Arquitetura da Informação ser uma disciplina. Para ele:

a interdisciplinaridade evidenciada, bem como a presença de diferentes abordagens que a [Arquitetura da Informação] orientaram desde seu início até os dias atuais, reforçam suas características de disciplina científica pós-moderna, com uma constituição epistemológica fluida, versátil e adaptável que a permite dar respostas mais eficientes aos complexos e mutáveis problemas sociotécnicos da pós-modernidade (OLIVEIRA, 2014, p. 62).

Nesse sentido, optou-se, na presente proposta, por considerar a Arquitetura da Informação como sendo uma disciplina. Isso porque a literatura atual, que foi explorada em nossa explanação entende a Arquitetura da Informação como disciplina e não como campo.

Tem-se como marco para os estudos em Arquitetura da Informação os postulados por Morville e Rosenfeld (2006), de forma que não há como tratar do tema sem mencioná-los. Para Albuquerque e Lima-Marques (2011), a relevância do trabalho dos autores se deu pelo fato deles estabelecerem um estado prático para a disciplina e as perspectivas para ela a partir da influência dos conteúdos Web. Além disso, Morville e Rosenfeld (2006) apresentaram a Arquitetura da Informação como sendo a intersecção de três elementos - contexto, conteúdo e usuário.

Apesar de a proposta de Morville e Rosenfeld (2006) conceituar a Arquitetura da Informação apenas para o ambiente Web, não consideramos sua proposta reducionista. Isso porque a obra atendeu o propósito a que se destinou. Nesse sentido Albuquerque e Lima-Marques (2011, p.61) afirmam que:

[...] importa observar que os conceitos propostos por estes autores, longe de serem restritivos, representam passos interessantes no sentido de fornecer um corpo de 
conhecimentos sistematizados, assim como primeiros princípios sobre os quais se pode raciocinar para 0 desenvolvimento da disciplina.

Assim vê-se que Morville e Rosenfeld (2006) estruturaram sistematicamente conhecimentos sobre a Arquitetura da Informação, preocupação essa que não havia sido observada até então. Dessa forma, pode-se descrever que a Arquitetura da Informação por eles explorada é do tipo clássica.

Todavia, novos desafios tem se apresentado a essa disciplina. Desafios esses que emergem de um contexto pós-moderno de informação em todo espaço e a todo tempo. Com isso, o pensar sobre a Arquitetura da Informação unicamente em ambiente Web não é suficiente, pois as novas questões que têm surgido extrapolam os limites da Web.

Acerca disso Resmine e Rossati (2011) afirmam que a partir dos anos 2000 muitas coisas começaram a mudar. Os usuários passaram a ocupar de forma mais expressiva uma nova função - a de produtores de conteúdos. Além disso, os dispositivos pessoais e domésticos passaram a redefinir os limites do que era a computação. Dessa forma, a Arquitetura da Informação estava indo além das fronteiras da Web.

A partir disso a Arquitetura da Informação passa a ser difusa, e passa a abordar a ideia de espaços de informação, os quais não necessariamente estão em meio Web (RESMINI; ROSATI, 2011). A meta do profissional que intervê nesses espaços passa ser análoga a do arquiteto tradicional, ou seja, projetar espaços onde as pessoas passam muito tempo, tornando a experiência dessas pessoas em relação ao lugar que ocupam algo bom.

Compreendemos que nesse contexto o ponto fundamental, e que revela a relevância de se pensar e agir a partir de uma Arquitetura da Informação Pervasiva, é o fato de que as possibilidades trazidas pelas tecnologias da informação atuais, em que é possível estar conectado à rede em qualquer lugar, não traz certezas do contexto em que um dado produto de informação é consumido. E é nisso que está o grande desafio, e junto com ele a oportunidade de se repensar os fundamentos de uma Arquitetura da Informação que tenha por princípio a pervasividade.

Com essa possibilidade de Arquitetura da Informação Pervasiva questionamos a quem o termo "pervasiva" se refere, se à arquitetura ou à informação. A análise e revisão da literatura da área apontam que a informação é que é pervasiva. Para isso, Oliveira (2014) traz uma metáfora bastante propícia. O autor aponta que uma dada represa ou barragem retém um volume de água. Caso as barragens desse ambiente vierem a se romper, a água se espalharia para todos os espaços que encontrasse no seu percurso. A ideia de pervarsividade da água é semelhante a da ideia de pervasividade da informação, pois assim como a água que rompe as barreiras e invade os espaços, a informação digital invade os espaços da sociedade, podendo estar presente em ambientes 
digitais ou não digitais. Assim, pode-se afirmar que a natureza pervasiva da água e semelhante à natureza pervasiva da informação.

Neste exemplo consideramos pertinente refletir sobre a água, que como elemento material tangível, ao ultrapassar as barreiras dos reservatórios, afeta um mundo também material. Isso porque ela pode derrubar muros, invadir as casas e preencher espaços vazios. Já a informação pervasiva como elemento não tangível irá afetar um mundo material e também imaterial. Material tangível porque a informação pode ser apreendida nos mais diversos tipos de suportes, por exemplo. E intangível porque ela incide diretamente sobre as formas de aprender dos sujeitos que fazem uso da informação, e isso é uma propriedade subjetiva. Além disso, o fim da informação é a geração de conhecimento, e esse é fator exclusivo das subjetividades pessoais.

Outro aspecto que pode ser incorporado à metáfora de Oliveira (2014) é o fato de a água ao adentrar os ambientes irá mudar a estrutura daquele ambiente, irá tirar elementos do lugar, e poderá ou não ser absorvida. Tal fato não pode ser assegurado ao se tratar da informação pervasiva. Essa, ao adentrar um dado ambiente, pode ou não ser percebida, e não necessariamente será absorvida e mudará a condição daquele ambiente. Nesse sentido, vale-se retomar a célebre noção de Belkin e Robertson (1976) acerca de informação, citada por Pinheiro (2004), a qual é entendida como aquilo que tem a capacidade de alterar as estruturas. Nesse sentido, poderia se considerar que o elemento pervasivo que não implicar em alterações não pode ser considerado como informação. Tal alteração não se refere a algo necessariamente bom, mas diz respeito a uma mudança de condição. A capacidade de a informação se incorporar e integrar ao meio em que atua é chamada de ubiquidade.

A absorção ou não da água ao integrar-se a dado material ou ambiente remete à informação digital, que penetra os diversos produtos tecnológicos da atualidade, afirma Oliveira (2014). Assim como a absorção da água depende das características do material de que ela se aproxima, assim também é com a informação digital. As características dos dispositivos e a capacidade de seus ambientes de se adequarem ao contexto e a informação implicarão na forma dos indivíduos utilizarem ou não a informação digital. Com isso, como pontuado por Oliveira (2014), a ideia de os dispositivos tecnológicos permitirem a adequação da informação em seus ambientes se associa a ideia de responsividade.

Com isso, pode-se observar que a noção de pervasividade inclui dois outros elementos fundamentais: a ubiquidade e a responsividade. $O$ primeiro se refere à informação, enquanto o segundo às tecnologias (OLIVEIRA, 2014).

Um outro aspecto ressaltado por Oliveira (2014) é que Arquitetura da Informação Pervasiva se difere de outras abordagens da Arquitetura da Informação por lidar com objetos e fenômenos que são construídos com uma estrutura informacional ecológica e uma estrutura sistêmica complexa. Oliveira (2014, p. 134) ressalta que a estrutura informacional ecológica refere-se ao "[...] conjunto de espaços, ambientes, canais, 
mídias, tecnologias e sujeitos com seus comportamentos, todos interligados e conectados de maneira holística pela a informação". Mesmo com vários elementos conectados, por se tratar de uma ecologia informacional, considera-se que o elemento principal desse contexto é o ser humano, e a informação é o padrão que une todos os elementos. A complementar, os elementos supracitados são organizados de forma sistêmica. As partes que compõem o todo são heterogêneas, e os sujeitos agem em cada uma delas, de forma que as relações estabelecidas são complexas.

Esse contexto de complexidades, oriundos de uma sociedade pósmoderna, o qual faz emergir a necessidade de uma Arquitetura Informacional atenta aos desafios de uma informação em todo o tempo e lugar nos encaminha a questionar o cenário da Ciência da Informação no qual essa estrutura se faz presente, e qual seria a perspectiva dessa ciência mais propícia para a compreensão de tais desafios.

\section{Tempos e paradigmas da ciência da informação}

Mediante a compreensão da dimensão e abrangência da Arquitetura da Informação Pervasiva como abordagem correlata à Arquitetura da Informação, questionamos em qual contexto da Ciência da Informação tal disciplina teria condições de melhor ser compreendida. Como se sabe, a trajetória dessa ciência tem diferentes tempos, cada um deles com um paradigma. Para compreensão desses tempos e paradigmas se recorrerá à Barreto (2002; 2008) e Capurro (2003). É importante destacar que tais tempos e paradigmas não se anulam ou se sobrepõem, eles apenas revelam o enfoque da área em diferentes momentos (BARRETO, 2002; 2008).

Tem-se o tempo da gerência da informação como o primeiro momento da Ciência da Informação. Ele se inicia em um período em que as teorias existentes não eram suficientes para lidar com o aumento significativo da quantidade de informações. Os instrumentos disponíveis para organizar as informações não eram adequados, de forma que foi necessária a definição de métodos que permitissem que os conteúdos dos documentos pudessem ser representados por indicadores. Assim surgem as linguagens de classificação, indexação e os tesauros (BARRETO, 2002; 2008).

Vê-se que o elemento principal desse tempo da Ciência da Informação é o controle da informação. Por essa razão, pode-se observar que tal tempo está relacionado ao paradigma físico da informação. Isso porque a Ciência da Informação se inicia como uma teoria da recuperação da informação, e essa está pautada numa epistemologia fisicista (CAPURRO, 2003). Esse paradigma se constrói a partir da teoria da informação de Shannon e Weaver, como afirma Ellis (1992) e Ørom (2000) citado em Capurro (2003). Essa teoria, conhecida também como Teoria Matemática da Comunicação, entende a informação sob um olhar técnico. Não são o foco da teoria os aspectos epistemológicos ou 
ontológicos da informação; a preocupação está sob a transmissão de dada quantidade de informação (GONZALEZ; NASCIMENTO; HASELAGER, 2004). Dessa forma, o aspecto principal do paradigma físico é o controle da informação, justificando assim o exposto por Capurro (2003, p. 7) ao afirmar que "[...], o paradigma físico tem suas raízes bem como seu sentido em atividades clássicas dos bibliotecários e documentalistas".

O segundo tempo da Ciência da Informação é o tempo da relação informação e conhecimento. Nele a informação tem o objetivo de gerar conhecimento nas realidades dos sujeitos que dela se apropria. Dessa forma, Barreto (2002) destaca que a ênfase nesse tempo está na ação da informação na coletividade.

O paradigma da Ciência da Informação que pode ser observado nesse contexto do tempo da relação informação e conhecimento é o paradigma cognitivo. Isso porque o enfoque desse paradigma é analisar as formas pelas quais os processos informativos transformam ou não os sujeitos.

O tempo atual ${ }^{2}$ da Ciência da Informação é o tempo do conhecimento interativo, em que a condição da informação e da comunicação são alteradas pela predominância das tecnologias da informação e comunicação (BARRETO, 2002; 2008). O conhecimento passa para um novo status a partir do desenvolvimento da Word Wide $W e b$, de forma que a interatividade se refere à possibilidade de acesso em tempo real aos diversos estoques de informação, agora desterritorializados, disponíveis na Web e fora dela. Aqueles que eram outrora usuários tornam-se sujeitos ativos na construção desse novo contexto, de forma que a inteligência coletiva, mesmo que não planejada, é prática valorizada. Não há mais distinções entre produtores e consumidores de conteúdos na rede. Os papeis são múltiplos, assim como os interesses e identidades desses sujeitos.

Nesse sentido, o sujeito é elemento central no tempo do conhecimento interativo. Por essa razão, considera-se o paradigma social como o predominante nesse tempo da Ciência da Informação. No referido paradigma o sujeito é entendido a partir dos seus condicionamentos sociais e materiais. Os sujeitos, que não são apenas usuários, mas participantes ativos da construção do conhecimento, são centrais para a definição e elaboração de dispositivos que considerem sua visão de mundo nos processos de recuperação da informação. Por essa razão Almeida et al. (2007, p. 22) afirmam que o paradigma social...

[...] enfoca a recuperação dos elementos subjetivos dos usuários para a definição do desenho dos sistemas de recuperação, considerando sua visão de mundo. A partir dessa concepção, a Ciência da Informação volta-se para um enfoque

2 Optou-se por "tempo atual" e não "último tempo" da Ciência da Informação porque acreditamos que essa é uma ciência em construção, que não está finalizada e tampouco tem essa pretensão, haja vista que os desafios que surgirão futuramente encaminharão a novos questionamentos que implicarão em novos tempos e novos paradigmas. 
interpretativo, centrado no significado e no contexto social do usuário e do próprio sistema de recuperação da informação.

Capurro (2003) destaca ainda a chamada "análise de domínio" como sendo o paradigma social-epistemológico cunhado por Birger Hjørland e Hanne Albrechtesen (HJØRLAND, 2003). Nesse paradigma o entendimento dos campos cognitivos está relacionado com os diferentes grupos sociais e de trabalho, os quais são denominados de "comunidades discursivas". Para a análise de domínio, o conhecimento é o resultado da interação do indivíduo com o meio em que ele está inserido (ALMEIDA et al., 2007).

A implicação prática destacada por Capurro (2003) acerca do paradigma social é que não se busca mais uma linguagem ideal para representar o conhecimento, ou um algoritmo para modelar a recuperação da informação, como se via nos paradigmas destacados anteriormente. Isso porque as bases de dados são polissêmicas, e os termos de um léxico podem ser alterados. Dessa forma, se faz necessário que os padrões de representação forneçam pontos de acesso que incluam a diversidade dos contextos dos sujeitos.

Capurro (2003), apoiando-se em Hjørland (2003), destaca que o foco da Ciência da Informação é estudar as relações entre discursos, áreas do conhecimento e documentos em relação às possíveis expectativas e pontos de acesso de diferentes comunidades de usuários. Integrar o individualismo do paradigma cognitivo e a visão de análise de domínio do paradigma social é um desafio metodológico para a Ciência da Informação (ALMEIDA et al., 2007).

Assim, consideramos que o objetivo da Arquitetura da Informação Pervasiva como abordagem de uma disciplina torna-se bastante pertinente para o contexto do tempo do conhecimento interativo e do paradigma social da Ciência da Informação em que os sujeitos estão imersos numa diversidade de ambientes, com diferentes linguagens oriundas da imbricação tecnológica, necessitando se orientar no translado entre esses ambientes. A incorporação do ponto de vista dos sujeitos que permeiam esses ambientes, no que se refere à representação e apresentação das informações, pode contribuir para vivências mais significativas e satisfatórias para os indivíduos que compõem o tempo do conhecimento interativo.

\section{0 paradigma social e o tempo do conhecimento interativo: um contexto possível para o entendimento da arquitetura da informação pervasiva}

Alguns fatores levaram-nos a considerar que a Arquitetura da Informação Pervasiva é uma abordagem presente, e mais do que isso, necessária no tempo do conhecimento interativo, e, por conseguinte, no paradigma social da Ciência da Informação. E é sobre isso que discorreremos a partir daqui. 
O primeiro fator que se faz necessário destacar é que o tempo do conhecimento interativo e o paradigma social colam o ser humano como elemento central das discussões. As preocupações estão voltadas não apenas para a atenção às necessidades isoladas dos indivíduos, porém mais do que isso, para compreendê-las a partir do entendimento da coletividade em que os sujeitos estão inseridos. Os interesses na gestão dos conteúdos informacionais, bem como as formas de apresentação dos mesmos, estão voltados para a coletividade e não mais para os gestores de conteúdos, fator esse que leva Le Coadic (2004) a identificar esse fato também como uma mudança de paradigma na área de Ciência da Informação.

Como apontado por Potente e Salvini (2009), a participação dos usuários no melhoramento dos processos de arquitetura e design de ambientes informacionais são fundamentais para se saber o que eles precisam em relação as funções e aos conteúdos a serem disponibilizados. Além disso, pode-se saber a forma pela qual esses usuários reconhecem e interagem com as informações disponíveis.

A participação efetiva dos usuários na rede não se refere apenas à colaboração na construção de conteúdos, mas também às formas pelas quais o usuário é envolvido para a construção dos ambientes informacionais, sejam eles digitais ou não. Nesse sentido, Potente e Salvini (2009, p. 41, tradução nossa) destacam que a

[...] estratégia de design participativo é a resposta porque ela oferece uma abordagem de projeto que se atenta a envolver proativamente os usuários finais no processo do projeto e ajuda a assegurar que o produto desenvolvido atenda suas necessidades e é utilizável.

Outro fator a se destacar que reforça que o tempo do conhecimento interativo é contexto apropriado para o entendimento da Arquitetura da Informação Pervasiva é a imbricação tecnológica presente nesse tempo (BARRETO, 2002), que vai ao encontro do observado pela disciplina em questão. Tal imbricação refere-se às varias linguagens de informação como a textual, a imagética e a sonora reunidas numa mesma estrutura digital. Tais linguagens, na estrutura de uma Arquitetura da Informação Pervasiva, permeiam os diversos ambientes, indo além dos digitais. Não estando em sincronia, e se não incorporarem a perspectiva de seu público alvo por meio de um design participativo, tais linguagens podem não favorecer a assimilação do conhecimento por parte dos sujeitos.

Destaca-se também a noção de temporalidade presente no contexto do tempo do conhecimento interativo. Para entender isso, recorremos à Lévy (2003) e as concepções de espaços antropológicos por ele apresentada. Entende-se que o espaço em que o tempo do conhecimento interativo se apresenta é o chamado Espaço do Saber, o qual tem por princípio a centralidade dos indivíduos para a construção do conhecimento por meio da valorização da inteligência coletiva. Pode-se observar a noção 
de tempo desse contexto por meio do próprio ritmo de aprendizagem dos sujeitos que compõe esse espaço. Esses sujeitos seguem um ritmo pessoal de aprendizagem. Nesse sentido, Lévy (2003) destaca que os sujeitos se valem de um tempo subjetivo. É um tempo que advém, se caracterizando como um tempo bergsoniano, mais do que um tempo newtoniano. Isso porque, não é um tempo unidirecional, como o da física clássica de Newton; mas é um tempo contínuo e indivisível, é um tempo como duração, como o defendido por Bergson (AMORIM; HABITZREUTER, 2010).

Pelo fato de o tempo ser construído a partir das subjetividades dos sujeitos e ser um tempo contínuo, é necessário que os ambientes que proporcionarão a aprendizagem dos indivíduos forneça estruturas capazes de permitir que os processos de aprendizagem sejam construídos de forma a incorporar essa perspectiva.

Os sujeitos, por exemplo, iniciam seus processos de busca a partir de um questionamento em ambiente analógico, efetuam a busca em um ambiente digital, e aplicam a informação obtida em ambos os ambientes. Não há um roteiro pré-estabelecido para essa aprendizagem, é não há uma duração para esse processo. Sabe-se que em tempos de pósmodernidade o tempo sempre será o de agora, e informação é sempre para ontem, mas compreende-se que aprendizagem é contínua, e é definida pelas subjetividades individuais. Por isso, considera-se que os ambientes projetados com os princípios de uma Arquitetura da Informação Pervasiva devem favorecer esses processos, apresentando estruturas de navegação amigáveis e persistentes.

É na construção desses espaços de informação, nas representações e organização dos conteúdos neles disponíveis que estará a real atuação do profissional da informação. Os processos de mediação da informação se tornarão menos explícitos, e os usuários cada vez mais autônomos no processo da construção do conhecimento.

\section{Considerações finais}

A complexidade da sociedade pós-moderna apresenta desafios consideráveis para o desenvolvimento científico e tecnológico. A multiplicidade de espaços informacionais requer um repensar das ciências que se atêm à investigação e ação em tais ambientes.

A Ciência da Informação, a partir de seu caráter interdisciplinar, apresenta a Arquitetura da Informação como disciplina que viabiliza a estruturação sistemática de espaços informacionais digitais. A transação de sujeitos pela diversidade de espaços informacionais, sendo eles digitais ou não, lança desafios aos postulados da Arquitetura da Informação clássica. A partir disso, há um questionamento acerca da aplicabilidade de tais sistemáticas nos variados ambientes de informação que atua como mola propulsora para as investigações na chamada Arquitetura da Informação Pervasiva. 
A Arquitetura da Informação Pervasiva requer consolidação, aprofundamentos, e antes de tudo, sua compreensão no escopo da Ciência da Informação. Para isso, considera-se que a observação de sua abordagem como disciplina no âmbito do tempo do conhecimento interativo e do paradigma social da Ciência da Informação se faz necessária para o entendimento de fundamentação histórica e epistemológica na ciência em questão.

Observou-se que a centralidade nas necessidades dos usuários, a diversidade de linguagens informacionais, e o tempo de aprendizagem dos sujeitos como um continuo são características do tempo do conhecimento interativo e do paradigma social da Ciência da Informação que devem ser observadas na construção de ambientes informacionais projetados a partir de uma Arquitetura da Informação Pervasiva.

Ademais, considera-se que os profissionais na informação terão papel fundamental, mas implícito, nos processo de estruturação dos ambientes a partir da aplicação de uma Arquitetura da Informação Pervasiva. Entendemos que seu papel principal será o de projetar esses espaços, observando para isso as necessidades de seus usuários, a diversidade de linguagens informacionais possíveis, e os ritmos de aprendizagem dos sujeitos. Seu papel será o de facilitador no transladar de um espaço informacional para outro, de forma a causar menos desgaste possível aos sujeitos que perpassam continuamente tais ambientes.

\section{Referências}

ALBUQUERQUE, A. R. R; LIMA-MARQUES, M. Sobre os fundamentos da Arquitetura da Informação. Perspectivas em Gestão \& Conhecimento, João Pessoa, v. 1, p. 60-72, 2011. Disponível em: $<$ http://periodicos.ufpb.br/ojs/index.php/pgc/article/view/10827/6075 > . Acesso em: 23 jan. 2015.

ALMEIDA, D. P. R. et al. Paradigmas contemporâneos da Ciência da Informação: a recuperação da informação como ponto focal. Revista Eletrônica Informação e Cognição, [Marília], v. 6, n. 1, p. 16-27, 2007. Disponível $<$ http://www.brapci.ufpr.br/documento.php?dd0=0000005406\&dd1 $1=e a 453$ > Acesso em: 4 jul. 2012.

AMORIM, W. L.; HABITZREUTER, V. Contingência e liberdade em Henri Bergson. Revista Interdisciplinar Científica Aplicada, Blumenau, v. 4, n. 1, p. 21-33, jan. 2010. Disponível em: <http://rica.unibes.com.br/index.php/rica/article/viewFile/358/316 > . Acesso em: 15 maio 2012.

BARRETO, A. A. A condição da informação. São Paulo em Perspectiva, [São Paulo], v. 16, n. 3, p. 67-74, 2002. Disponível em: $<$ http://dx.doi.org/10.1590/S0102-88392002000300010>. Acesso em: 15 maio 2012. 
BARRETO, A. A. Uma quase história da ciência da informação. DataGramaZero: revista de Ciência da Informação, [Rio de Janeiro], v. 9, n. 2, abr. 2008. Disponível em: <http://www.dgz.org.br/abr08/Art 01.htm>. Acesso em: 24 fev. 2013.

BELKIN, N. J.; ROBERTSON, S. E. Information Science and the phenomena of information. Journal of the American Society for Information Science - JASIS, [S.I.], v. 27, n. 4, p. 197-204, jul./ago. 1976. Disponível em: <http://dx.doi.org/10.1002/asi.4630270402>. Acesso em: 4 dez. 2015.

CAMARGO, L. S. A.; VIDOTTI, S. A. B. G. Arquitetura da informação para biblioteca digital personalizável 10.5007/15182924.2006v11nesp1p103. Encontros Bibli: revista eletrônica de Biblioteconomia e Ciência da Informação, Florianópolis, v. esp., 10 sem., p. 103-118, nov. 2007. Disponível em: <https://periodicos.ufsc.br/index.php/eb/article/view/15182924.2006v11nesp1p103/389 >. Acesso em: 10 jan. 2015.

CAPURRO, R. Epistemologia e Ciência da Informação. In: ENCONTRO NACIONAL DE PESQUISA EM CIÊNCIA DA INFORMAÇÃO, 5., 2003, Belo Horizonte. Anais... Belo Horizonte: Universidade Federal de Minas Gerais, 2003. Disponível em: <http://www.capurro.de/enancib p.htm>. Acesso em: 15 ago. 2011.

ELLIS, D. Paradigms and proto-paradigms in information retrieval research. In: VAKKARI, P. Conceptions of Library and Information Science: historical, empirical and theoretical perspectives. London: [s.n.], 1992. p. $165-186$.

GONZALEZ, M. E. Q.; NASCIMENTO, T. C. A.; HASELAGER, W. F. G. Informação e conhecimento: notas para uma taxonomia da informação. In: FERREIRA, A.; GONZALEZ, M. E. Q.; COELHO, J. G. Encontro com as ciências cognitivas. São Paulo: Cultura Acadêmica, 2004. v. 4. p. 195220.

HAVERTY, M. Information Architecture without internal theory: an inductive design process. Journal of the American Society for Information Science and Technology, [S.I.], v. 53, n. 10, p. 839-845, 2002. Disponível em: <http://onlinelibrary.wiley.com/doi/10.1002/asi.10096/pdf >. Acesso em: 23 jan. 2015.

HJØRLAND, B. Epistemology and the Socio-Cognitive Perspective in Information Science. Journal of the American Society for Information Science and Technology, [S.I.], v. 53, n. 4, p. 257-270, 2003. Disponível em: $\quad<$ http://web.ebscohost.com/ehost/pdfviewer/pdfviewer?sid=b9948c40-36d0497d-817b-ba54891ac065\%40sessionmgr13\&vid=1\&hid=14 >. Acesso em: 4 jul. 2012.

LE COADIC, Y. A Ciência da Informação. 2. ed. Brasília: Briquet de Lemos, 2004.

LÉVY, P. A inteligência coletiva: por uma antropologia do ciberespaço. 4. ed. São Paulo: Loyola, 2003. 
MORVILLE, P.; ROSENFELD, L. Information for architecture for the Word Wide Web. 3. ed. Sebastopol: O'Reilly, 2006.

OLIVEIRA, H. P. C. Arquitetura da informação pervasiva: contribuições conceituais. 2014. 202f. Tese (Doutorado em Ciência da Informação) Faculdade de Filosofia e Ciências, Universidade Estadual Paulista, Marília, 2014. Disponível em: <http://hdl.handle.net/11449/110387>. Acesso em: 11 jan. 2015.

ØROM, A. Information science, historical changes and social aspects: a nordic outlook. Journal of Documentation, [S.I.], v. 56, n. 1, p. 12-26. 2000. Disponível em: <http://dx.doi.org/10.1108/EUM0000000007133>. Acesso em: 4 dez. 2015.

PINHEIRO, L. V. R. Informação - esse obscuro objeto da Ciência da Informação. Morpheus, ano 2, n. 2, 2004. Disponível em: $<$ http://www.unirio.br/morpheusonline/Numero04-2004/lpinheiro.htm>. Acesso em: 23 jan. 2015.

POTENTE, D.; SALVINI, E. Apple, IKEA and their integrated architecture. Bulletin of the American Society for Information Science and Technology, [S.I.], v. 35, n. 4, p. 32-42, 2009. Disponível em: $<$ https://www.asis.org/Bulletin/Apr-09/AprMay09 Potente-Salvini.pdf>. Acesso em: 23 jan. 2015.

RESMINI, A.; ROSATI, L. Pervasive information architecture: designing cross-channel user experiences. Burlington: Elsevier, 2011.

SARACEVIC, T. Ciência da informação: origem, evolução e relações. Perspectivas em Ciência da Informação, Belo Horizonte, v. 1, n. 1, p. 4162, jan./jun. 1996. Disponível em: <http://portaldeperiodicos.eci.ufmg.br/index.php/pci/article/viewFile/235/22>.

Acesso em: 9 mar. 2011

SOUZA, M. R. F.; PÁDUA, M. C. Arquitetura da Informação Pervasiva: desvendando as heurísticas de Resmini e Rosati. Informação \& Tecnologia (ITEC), Marília, v. 1, n.1, jan./jun., 2014. Disponível em: $<$ http://periodicos.ufpb.br/ojs/index.php/itec/article/view/19294/11001>. Acesso em: 23 jan. 2015. 